Studying infrastructuring ethnographically

Helena Karasti, University of Oulu, Finland

Jeanette Blomberg, IBM Research, San Jose, California, USA

Corresponding author

Helena Karasti

INTERACT Research Unit

University of Oulu

Finland

+358407093606

helena.karasti@oulu.fi

This is a post-peer-review, pre-copyedit version of an article published in Computer Supported Cooperative Work (CSCW): The Journal of Collaborative Computing and Work Practices, vol. 27, no. 2, pp. 233-265. The final authenticated version is available online at:

http://dx.doi.org/10.1007/s10606-017-9296-7

A full-text view-only version available via:

http://rdcu.be/uzPj 


\title{
Studying infrastructuring ethnographically
}

\author{
Helena Karasti, University of Oulu, Finland \\ Jeanette Blomberg, IBM Research, San Jose, California, USA
}

\begin{abstract}
This paper is motivated by a methodological interest in how to investigate information infrastructures as an empirical, real-world phenomenon. We argue that research on information infrastructures should not be captive to the prevalent method choice of small-scale and short-term studies. Instead research should address the challenges of empirically studying the heterogeneous, extended and complex phenomena of infrastructuring with an emphasis on the necessarily emerging and open-ended processual qualities of information infrastructures. While existing literature identifies issues that make the study of infrastructuring demanding, few propose ways of addressing these challenges. In this paper we review characteristics of information infrastructures identified in the literature that present challenges for their empirical study. We look to current research in the social sciences, particularly anthropology and science and technology studies (STS) that focus on how to study complex and extended phenomena ethnographically, to provide insight into the study of infrastructuring. Specifically, we reflect on infrastructuring as an object of ethnographic inquiry by building on the notion of "constructing the field." Recent developments in how to conceptualize the ethnographic field are tied both to longstanding traditions and novel developments in anthropology and STS for studying extended and complex phenomena. Through a discussion of how dimensions of information infrastructures have been addressed practically, methodologically, and theoretically we aim to link the notion of constructing the ethnographic field with views on infrastructuring as a particular kind of object of inquiry. Thus we aim to provide an ethnographically sensitive and methodologically oriented "opening" for an alternative ontology for studying infrastructuring ethnographically.
\end{abstract}

Keywords: anthropology, collaborative design, constructing the field, dimensions of information infrastructure, ethnography, information infrastructure, infrastructuring, object of inquiry, reflexivity, science and technology studies 


\section{Introduction}

Increasingly, researchers, including those in design fields, have recognized that the study of information infrastructures necessitates new methods (Tilson et al. 2010; Pollock and Williams 2010; Williams and Pollock 2012; Blomberg and Karasti 2013; Edwards et al. 2013; Ribes 2014; Karasti et al. 2016b). However, most efforts focus on investigating and defining the phenomenon of information infrastructures (e.g. Edwards et al. 2007, 2009; Monteiro et al. 2014; Bowker et al. 2010; Appel et al. 2015) with less attention on how information infrastructures can be studied empirically. This paper builds on and continues from the early work by Star and colleagues (Star and Ruhleder 1994, 1996; Star 1999; Bowker and Star 1999) by focusing on how to ethnographically study information infrastructures. In her 'Ethnography of Infrastructure' paper (1999) Star encouraged researchers "to study the unstudied" and to take up new challenges related to investigating infrastructures ethnographically, where scaling up from traditional ethnographic sites, managing large quantities of data, and taking account of the interplay of online and offline behavior are identified as important considerations. In this paper we make the ethnographic study of information infrastructures our focus by taking the empirical component of infrastructuring, or in ethnographic terms the "field", as our topic of inquiry.

The paper builds on discussions in anthropology that (re)invigorated critical debate on the role of the ethnographer in "constructing the field" which arose in relation to globalization discourses and critical reflection on the place of ethnography in the study of complex and extended phenomena. While these methodological deliberations have roots in anthropology (e.g. Gupta and Ferguson 1997; Amit 2000), they also are widely recognized in qualitative, fieldwork-based social sciences, and serve to remind us that the ethnographer is always an active participant in constructing the field, even in studies of the single location field site (Marcus 1995, 1998; Gupta and Ferguson 1997; Amit 2000).

We argue that in studies of infrastructuring, i.e. the ongoing and continual processes of creating and enacting information infrastructures, researchers are engaged in constructing the field through the myriad of choices they make about what aspects of the complex and extended phenomenon deserve their focus. An essential tenet in empirically studying infrastructuring (as in all ethnographic studies) is explicit deliberation and reflection on how the field is reflexively constructed and the implications this has for our understanding of the phenomenon of study and for delineating the object of inquiry (Blomberg and Karasti, 2013). Larkin makes a related observation by asserting that the designation of 'an infrastructure is a categorical act' (2013, p. 330). As such when studying complex, spatially and temporally extended phenomena that simply cannot be studied "as wholes", attention is required on how ethnographic fields are carved out and put together ("constructed") by the investigator (Blomberg and Karasti 2013). This is not a straightforward task, accomplished in a single movement. It is an ongoing activity, required of all studies no matter their complexity or duration. In this sense the study of infrastructuring is well aligned with current considerations on how the ethnographic field is constructed. 
Many of the methodological advances in the study of extended and complex phenomena in the social sciences have remained outside the awareness of CSCW and related design fields. Descriptions of how the field is constructed are extremely rare (notable exceptions are Henriksen 2002; Winthereik et al. 2002; Parmiggiani 2017), despite the fact that defining the field is an inevitable, "practical" component of every empirical study of information infrastructures. Even the loudest critics of relying on the accustomed short-term and small-scale research designs and scopes have largely limited their suggestions for alternative approaches to specific techniques such as "Biography of Artefacts" (Pollock and Williams 2010) and "scalar devices" (Ribes 2014).

What we propose in this paper is to continue and extend the work that Star and colleagues (Star and Ruhleder 1994, 1996; Star 1999) began with specific consideration for how the well-known characteristics of information infrastructures shape the possibilities for an ethnography of infrastructuring. We take stock of existing research, both initial and current, on information infrastructures that characterizes the phenomenon and relate these findings to developments and advances in the ethnographic study of complex, extended phenomena. Based on this we propose that the ethnographic investigation of infrastructuring can be guided by attention to a set of dimensions that speak to the ontology of infrastructures. We want to emphasize our desire to move the discussion beyond simply proposing techniques that aid in defining the field to a research program that addresses the interplay between the ontology of information infrastructures and the ethnographic study of complex, extended phenomenon. This paper can be read as our attempt to provide an ethnographically sensitive and methodologically oriented "opening" for an alternative ontology for studying infrastructuring ethnographically.

Through an iterative process of analysis, reflection and synthesis we examined the existing literature on information infrastructures in relation to our own empirical investigations of infrastructures. We grouped the characteristics into a set of five dimensions discussed in section 2 to facilitate our exploration of the challenges faced by those wanting to study infrastructures ethnographically and to aid in developing possible methodological and theoretical ways forward. Deciding on the groupings was informed by our review of literature discussing developments and advances in the study of complex, extended phenomena (mainly in anthropology and STS) some of which directly addressed our topic area of (information) infrastructures. Our perspectives about how to study infrastructuring ethnographically were also informed by reflecting on our past and ongoing research on complex, extended phenomena. There are clear connections between the dimensions presented in section 2 and our proposals for what is required to study infrastructuring ethnographically as outlined in section 3. For example, the dimension of relational is foundational for "constructing the field", the dimensions of connected and emerging and accreting are associated with "pursuing the phenomenon", and the dimension of invisible lays the groundwork for "inversing infrastructural relations".

While our focus is on information infrastructures, we use the term infrastructure as a shorthand and also in reference to literature with more general interest in infrastructures. Additionally, while the terms infrastructure and infrastructuring are at times used interchangeably in the literature, we want to distinguish them to 
highlight two distinctly different analytical concepts. When we use the term (information) infrastructure we are concerned with characteristics of a phenomenon such as "relational" (e.g. Star and Ruehleder 1994, 1996), whereas our use to the term infrastructuring is meant to direct attention to the more "processual" qualities through which the phenomenon emerges (e.g. Star and Bowker 2002; Karasti and Baker 2004; Karasti and Syrjänen 2004; Pipek and Wulf 2009). In this article, we are using the term information infrastructures when we describe characteristics and dimensions of the phenomenon of interest. When discussing the empirical study of the phenomenon, the notion of infrastructuring is used to denote the open-ended, uncertain and dynamic, qualities of the phenomenon (some still uncharted) that render their study challenging.

\section{Dimensions of information infrastructures}

This section takes stock of existing research that characterizes the phenomenon of information infrastructures. We describe a set of five dimensions of information infrastructures that we synthesized from a review of frequently identified characteristics and from our own research - (1) the profoundly relational quality of infrastructures, (2) the intrinsic (at least partial) invisibility of infrastructures, (3) the connectedness of infrastructures, sometimes described as "scaling," (4) the emerging and accreting quality of infrastructures, and (5) the role of intentionality and intervention in delineating infrastructures. The relational, invisible and connected dimensions figured centrally into Star and colleagues' initial characterizations of information infrastructures (Star and Ruhleder 1994, 1996; Star 1999; Bowker and Star 1999) ${ }^{1}$. The dimension emerging and accreting has become a more prominent focus of research on information infrastructures in recent years. Lastly, the dimension intervention and intentionality was added to address the role of design in infrastructuring.

We offer two recent, often cited, definitions of information infrastructures to highlight that they are complex, socio-technically imbricated phenomena that require new approaches to their study.

First, Edwards et al. (2013, p. 5) emphasize that infrastructures have a

'modular, multi-layered, rough-cut character... [that] are not systems, in the sense of fully coherent, deliberately engineered, end-to-end processes. Rather, infrastructures ... consist of numerous systems, each with unique origins and goals, which are made to interoperate by means of standards, socket layers, social practices, norms, and individual behaviors that smooth out the connections among them.'

Second, Monteiro et al. (2013, p. 576) characterize information infrastructures by their

'... openness to number and types of users (no fixed notion of "user"), interconnections of numerous modules/systems (i.e. multiplicity of purposes, agendas, strategies), dynamically evolving portfolios of (an ecosystem of) systems and shaped by an installed base of existing systems and practices (thus restricting the scope of design, as traditionally conceived) [and by being] ... stretched across space and time: ... shaped and used across many different locales ... over long periods (decades rather than years).' 


\section{1 - Relational}

As Star and Ruhleder put it, infrastructures are fundamentally relational, emerging in situ in relation to organized practices where infrastructures are connected to particular activities. As an example, within a "western" context, the cook considers the water system as working infrastructure integral to preparing dinner, for the city planner it is a variable in a complex planning process, and for the plumber it is a target for repair. 'Analytically, infrastructure appears only as a relational property, not as a thing stripped of use.' (Star and Ruhleder 1996, p. 113) Several of the characteristics through which infrastructures emerge, as suggested by Star and Ruhleder (ibid.), highlight different facets of the relational quality of infrastructures as "embedded" in, "sunk" into, other structures, social arrangements and technologies. This emphasizes the dense, socio-technical imbrication (Star 2002) of infrastructures that shape and are shaped by the conventions of a community of practice' (Star and Ruhleder 1996, p. 113). Infrastructures 'build upon an installed base' that has inherited strengths and limitations (inertia)' (ibid.). Understanding the relational nature of infrastructures involves unfolding the technical, social, political and ethical choices made throughout the design and development of infrastructures (Clarke and Star 2008).

\section{2 - Invisible}

Maybe the most elusive quality of information infrastructures is that they appear unremarkable. Infrastructures are the "substrate" that allows other things (the "substance") to happen. Infrastructures achieve their largest effects by being out of the way, taken for granted and sometimes deliberately hidden (Appadurai 2014). Good, usable infrastructures disappear almost by definition: the easier they are to use, the harder they are to see (Bowker and Star 1999, p. 33). However, making infrastructures invisible is, in fact, an outcome of considerable effort, work and investment.

Star and Ruhleder highlight infrastructures' invisible quality from a variety of angles. Infrastructures are typically of mundane and unexciting nature, they tend to fade into the background by both design and habit. They become taken for granted, once their use has been 'learned as part of membership' in a community of practice (Star and Ruhleder 1996, p. 113). When infrastructures work well, they 'just [are] there, readyto-hand, completely transparent' (ibid., p. 112), akin to Heidegger's example of the hammer, highlighting the invisibility of tools in everyday life (1962). The infrastructure does not have to be reinvented each time, but invisibly supports the task at hand. Therefore, the infrastructure's users are relatively unaware of it and how it works. The normally invisible quality of infrastructure 'becomes visible when it breaks' (Star and Ruhleder 1996, p. 113), similar to Heidegger's notion of "presentat-hand" (1962).

While invisibility is certainly an aspect of infrastructures, their invisibility is not at all times. Larkin describes the (in)visibilities of infrastructures as ranging 'from unseen to grand spectacles and everything in between' (Larkin 2013, p. 336). From a methodological point of view, however, the spectacular as highly noticeable is often easier to deal with, while of greater challenge is the "unseen", the hard to perceive and notice. The issue is not an invisibility of a typical anthropological strangeness, but 
rather 'an embedded strangeness, a second-order one, that of the forgotten, the background, the frozen in place' (Star 1999, p. 379). The invisibility of infrastructure has to be first "unfrozen", brought to the foreground from obscurity, before it can even be noted as "everyday" or "exotic", "unremarkable" or "remarkable" in the anthropological sense.

\section{3 - Connected}

Our dimension of connected is closely related to the dimension of relational. As stated by Strathern an inherent property of a "relation" is that 'it requires other elements to complete it [...] for the relation always summons entities other than itself' (Strathern 1995, p. 18). Aligned with this, is the connectedness or "scaling" of infrastructures where infrastructure 'has reach or scope beyond a single event or one-site practice, both temporally and spatially' (Star and Ruhleder 1996, p. 113). Connectedness as a characteristic of a phenomena brings together things of quite different scales (Strathern 1995, p. 19), thus the relational quality creates interdependent and inextricably linked phenomena that extends the infrastructures' socio-materialtechnical-political constellation. Through 'embodiment of standards' infrastructures become connected 'into other tools and infrastructures in a standardized fashion' (Star and Ruhleder 1996, p. 113).

As Ribes and Lee point out, in technology oriented discussions the connected quality of infrastructures is often referred to in straightforward, quantifiable ways, such as "scaling up" 'the number of collaborators, the quantity of data, availability of raw computing cycles or broader geographic reach' (Ribes and Lee 2010, p. 236). Scaling also can be understood in terms of spatial/geographical (small - large scale), temporal (short - long term) and local - global (Edwards et al. 2007, 2009). Relatedly, as a reminder to look across the full breadth of infrastructure activities, Ribes and Finholt (2009) suggest consideration of three "scales of infrastructure", enacting technology, the organization of work, and institutionalization.

The "reach or scope" of infrastructures' connectedness can be ethnographically and analytically thought of as increasingly dispersed and distributed in time and space, and together with increasingly mobile populations, intricate combinations of online and offline activities are engaged. The move from the more traditional (geo)spatial interests to new ways of conceptualizing infrastructures evokes understandings of scales and boundaries of infrastructures as open and open-ended (Edwards et al. 2007), never given but always contingent (Jensen and Winthereik 2013), and where the object of study is unbounded (Hine 2009).

\section{4 - Emerging and Accreting}

The quality of infrastructures as emerging and accreting has become a focus in recent years. Reflecting on infrastructures in-the-making through the lens of performativity, Star and Bowker (2002) point out that the stability of infrastructures is relative and needs to be produced in an ongoing manner through development and maintenance. The notion of performativity draws attention to how relations and boundaries between humans and technologies are not pre-given or fixed, but enacted (Mol 2002). The emerging quality of infrastructure formation may be characterized by uncertainty, including the heterogeneous processes of becoming and the associated temporal complexities full of ups and downs, false starts, disconnects, dead ends and 
failures. These prolonged processes, ongoing integrations, backing and forthing, expanding and retreating, create emerging infrastructures, so much in-the-making that they never fully exist in an absolute sense. This is related to the notion of "partially existing technology" (Latour 1999) that is 'rather wildly incoherent and only partially materialized', pulling 'in different directions' (Jensen and Winthereik 2013, p. 11). Given that infrastructures are always emerging, we can 'assume neither their stability nor their ability to connect' (ibid., p. 12) in a straightforward manner. However, 'vagueness is not a weakness of infrastructures; it is a condition for their emergence and workability' (ibid., p. 13).

The temporal quality of infrastructures as emerging over the long-term relates to the time scales over which they typically "accrete" (Anand 2015), or grow and take hold as intended long-term resources (Edwards et al. 2007, p. i). Although there may be attempts to assemble and align the heterogeneous elements simultaneously, this seldom works. 'Instead [infrastructure] formation is incremental, contiguous, and often dissynchronous' (Anand 2015, p. 1). Infrastructures gather slowly, they are grafted onto an already existing world ("installed base," Star and Ruhleded 1996) that both constrains and enables their form. Infrastructures gather various older and newer components that create fundamental "dependencies" (Pipek 2016, personal communication) and while bound together, seldom fully cohere (Anand 2015). Even the so-called more established infrastructures are hardly static. They may not perform as planned, they may break and splinter, or become subject to sabotage and hacking (Barry 2015). Infrastructures demand regular monitoring, upkeep and repair (Jackson 2014). If these are not attended to the ineluctable pull of decay and decline set in and infrastructures enter the long or short spiral into entropy that - if untended - is their natural fate' (Jackson 2015, p. 1).

\section{5 - Intervention and Intentionality}

Writing against prevalent views of infrastructures at the time, Ciborra (2000) recognized that dynamic and heterogeneous information infrastructures could not be controlled and built as systems because they were not fully coherent, deliberately engineered, end-to-end processes (Edwards et al. 2013). Highlighting the fundamental tension between the processes of planned versus emergent changes to infrastructures, Edwards et al. (2007) described the conflict between the intentionality of design and the unpredictability arising from complex relations and interactions.

In recent years the language for designing and developing infrastructure has changed. A more organic lexicon (ibid.), a family of "ing" terms, has been proposed, including "growing," "fostering," "encouraging," and "cultivating" (Edwards et al. 2007; Zimmerman and Finholt 2007; Karasti and Baker 2008; Hanseth 2010). These align well with Star's (1999, p. 382) initial ideas where infrastructure 'is fixed in modular increments, not all at once or globally [...] it is never changed from above [...] Changes take time and negotiation, and adjustment with other aspects of the systems are involved. Nobody is really in charge of infrastructure.'

Interventions, however, are not limited to research, design and development oriented activities. Edwards et al. broaden the engaged intentionalities by pointing to the diverse dynamics involved in infrastructure genesis, development and scaling where 
the form of an infrastructure is the result of converging histories, path dependencies, serendipity, innovation and bricolage (tinkering) (2007, p. 6-7). Moreover, the equivocal nature of infrastructure, is eloquently expressed by Edwards et al. (2009) in the following quote, '[infrastructure] seems an all-encompassing solution and an omnipresent problem, indispensable yet unsatisfactory, always already there; yet always an unfinished work in progress' (p. 365). The repertoire of intentional, generative (Zittrain 2006) activities considered in relation to infrastructures expands as heterogeneous actors' goals, purposes, agendas and strategies vary. Adding the role of regulations, standards setting, funding and policy formation, the "ing" terminology, including adapting, tailoring, appropriating, tuning, modifying, tweaking, making, fixing, monitoring, maintaining, repairing, hacking, vandalizing and instrumenting, points to a rich set of intentionalities that incrementally shape infrastructures (Karasti et al. 2006, 2010; Pipek and Wulf 2009; Kee and Browning 2010; Geiger and Ribes 2010; Jackson 2014, 2015; Wong and Jackson 2015; Wagenknecht and Korn 2016).

The variety of "ing" terminology highlights the many ways in which humans and nonhumans engage in various translation activities that are, as Larkin points out, inherent to systems building. Translation occurs as a networked infrastructure 'move(s) to other places with differing conditions, technological standards, and legal regulations, elaborating techniques of adaptation and translation' (Larkin 2013, p. 330). Intervening not only happens through intentional acts, but also is the result of the connecting and layering of infrastructures over time as they expand into different arenas and contexts.

\section{Studying infrastructuring ethnographically}

This section explores the intersection between the dimensions of information infrastructures discussed above and methodological developments in anthropology and STS that address the challenges of studying extended and complex phenomena with a specific focus on recent advances in how the ethnographic field is constructed and conceptualized. Specifically, in section 3.1 we introduce the notion of constructing the field as it has been discussed in the social science literature. Then in section 3.2 we explore how the dimensions of relational, connected, emerging and accreting, and intervention and intentionality relate to these recent developments. Finally, in section 3.3 we explore strategies for making the invisible accessible ethnographically. Our aim is to increase awareness of the particular methodological challenges inherent in studying infrastructuring ethnographically that are related to the 5 dimensions of infrastructure discussed in section 2 and to offer alternatives for addressing them.

To elaborate somewhat, in Section 3.1 we introduce the notion of constructing the field by questioning various taken-for-granted aspects of the field and offering other ways to conceptualize the field. Instead of viewing the field as a naturally occurring entity, the field as constructed introduces an alternative understanding of the field, where the ethnographer by constructing the field during fieldwork simultaneously engages in delineating the object of inquiry. Drawing further on literature from STS, we present an array of differently oriented conceptual perspectives on the field, 
which broaden and diversify the prevalent spatial trope often used to conceptualize the field and extend its boundaries.

In section 3.2 we build on the anthropological premise that the pursuit of a phenomenon of interest within an "empirical landscape" is not fixed. Instead, as we discuss in section 3.2.1, the phenomenon emerges by following connections and discovering discontinuities thus making more observable the dimensions of connected and emerging and accreting. In section 3.2.2 we continue by introducing a number of approaches that offer different methodological approaches for dealing with scaling that go beyond the simple multiplication of field sites. By considering, for instance connective, multi-sited, fractal, and recursive conceptualizations of the field, attention is drawn to the connected and emerging and accreting dimensions of infrastructure. In section 3.2.3 we continue by highlighting the researcher's agency in reflexively making choices regarding what to include or exclude from view. The openendedness and potential unboundedness of the field are explored as they concern the relational, connected, and emerging and accreting dimensions of information infrastructures.

Finally, in section 3.3 we introduce the notion of infrastructural inversion that directs attention to the disappearing, out-of-sight, invisible dimension of information infrastructures which poses a central problem for the empirical study of infrastructuring. Brought to the fore is also the mundane, background operations and unnoticed work that emphasizes the possibilities and limitations for how the dimension of interventions and intentionalities can play out in infrastructuring.

\subsection{Constructing the field}

The notion of constructing the field organizes around understanding the field as constructed, challenging the idea that "the "field" which ethnographers enter exists as an independently bounded set of relationships and activities, which is autonomous of the fieldwork through which it is discovered' (Amit 2000, p. 6). As Amit (ibid., p. 6) emphasizes,

'... in a world of infinite interconnections and overlapping contexts, the ethnographic field cannot simply exist, awaiting discovery. It has to be laboriously constructed, pried apart from all the other possibilities for contextualization to which its constituent relationships and connections could also be referred.'

Thus, as we argue (Blomberg and Karasti 2013, p. 389) the field is reflexively constructed 'by every choice the ethnographer makes in selecting, connecting, and bounding the site and via the interactions through which s/he engages with the material artifacts and the people who define the field.' Similarly, though with emphasis on epistemological and political commitments, Larkin notes that defining an infrastructure is a "categorical act" of "selecting what one sees as infrastructural [...] and what one leaves out' (2013, p. 330).

The researcher engages in forming the object of inquiry during fieldwork, informed by their interests and motivations and enabled by specific resources, situations and opportunities. The research interests, and the theoretical underpinnings (Hine 2009) inform the process of fashioning an object of ethnographic inquiry. Of particular emphasis is that the object of inquiry is relationally defined, and comes into being as a 
consequence of interactions in the field and from the engagement of the ethnographer with the phenomena.

The view of the field as constructed calls into question the assumption that the field is a naturally occurring entity such as the romanticized far away village in anthropology, the iconic exemplar of scientific laboratory in STS or the single-sited workplace in CSCW studies (Blomberg and Karasti 2013). Likewise, in studies of information infrastructures, it is necessary to question taken-for-granted notions of the field, such as the organization, the community, the design project and even the infrastructure (Karasti 2014), and engage with them as relationally constructed.

Noting that all study designs have embedded assumptions, Winthereik et al. (2002) encourage researchers to experiment with different ways of framing the object of study in order to identify constraints that might productively render the object of inquiry a surprise to the researcher. This helps address the risk of making "easy discoveries" that simply support initial assumptions. But even when surprises and transformations are allowed, if not pursued, predicting or controlling the study's focus and findings remains an impossibility as they emerge through ongoing engagement (ibid., p. 56).

Beyond being open to surprise and serendipity, it is important to reflect on the limitations of dominant spatial tropes that often are used to extend the field beyond the singularity of "this place". As researchers encounter increasingly dispersed and mobile populations engaged in intricate combinations of online and offline activities, they confront settings that include, for instance, face-to-face, co-located, online, IT mediated, ephemeral, sedentary, mobile, distributed contexts and their hybrid blends and varied assemblages. This demands that they critically reflect on demarcations of the field that remain fundamentally anchored in tropes of location and spatiality and look to non-spatially oriented notions of the field.

Spatially oriented notions of the field are sometimes conceptually paired with the temporally oriented ones. Proponents of temporally oriented ethnography consider the 'fundamental temporal properties that need to be examined ipso facto and not only by reference to a spatial trope' (Dalsgaard and Nielsen 2013, p. 8). Dalsgaard and Nielsen suggest 'that the field, as a confluence of different times and temporalities, emerges rather as a dynamic force of becoming that shifts in intensity and clarity, depending on the ethnographer's immediate position and immersion' (ibid., p. 6). Considering temporal aspect of the field not only 'implies a particular attention to the methodology of studying local (social and ontological) imaginaries of time', but also 'unpacks the (multi)temporality of the relationship between fieldworker and the field' (ibid., p. 1).

Recent critiques of temporally bounded, short-term design projects (Ehn 2008) have made more visible the temporal properties of the field in the study of information infrastructures. This has given rise to extending the field to include more open-ended, long-term processes of infrastructuring, such as those characterized by the notions of the long now (Ribes and Finholt 2009) and infrastructure time (Karasti et al. 2010). 
Consideration of mobilities as an orientation to constructing the field directs attention to how objects, people, ideas, practices and information move, become immobile, or are blocked from movement (Adey et al. 2014). To avoid privileging notions of boundedness and the sedentary there is a core commitment to mobile methods where researchers, often as participant observers, move with subjects of inquiry, following some selected objects and connections (Büscher et al. 2011). Furthermore, ethnographers are understood to purposively create the occasions for contacts that are 'episodic, occasional, partial, and ephemeral' as they study mobile individuals, diffuse processes and dispersed and/or fragmented social networks (Amit 2000, p. 14-15). In studies of information infrastructures, mobilities research promises to provide new ways of grasping the complex lived practices of mobilization and (im)mobilization (Büscher et al. 2011) associated with infrastructuring.

"Co-presence" has been put forward as an alternative to the notion of co-location that dominates the spatial trope (Beaulieu 2010). The idea is that co-presence 'decentralizes the notion of space without excluding it. It opens up the possibility that co-presence might be established through a variety of modes, physical co-location being one among others' (ibid., p. 454). Co-presence is not so much a redefinition of the field itself, but an approach to doing fieldwork. It generates new prospects for constructing the field that are not strongly tied to a physically defined space or faceto-face interaction. As a focus of fieldwork it elaborates upon the streams of practices (visible in interactions and inscriptions, i.e. texts and traces) that the ethnographer follows in highly mediated and distributed environments. Co-presence suggests an interesting new orientation for ethnographically studying infrastructuring. It foregrounds the relationship between fieldworker and the participants, and highlights the centrality of the interaction that achieves presence in a setting. Thus, a key issue for constructing the field becomes a distinct epistemic strategy of establishing co-presence that leads the fieldworker to ask, 'How can I establish copresence?' (ibid., p. 457). Co-presence as an orientation to constructing the field seems particularly relevant for settings where online and offline connections are pursued back and forth, as well as for fully online and distributed settings.

How the field is conceptualized has implications for the study of infrastructuring. Consideration of the constructed quality of the ethnographic field offers possibility for discovering new understandings of complex, extended phenomenon and supports an emphasis on the processual aspects of infrastructuring. We take up various approaches to pursuing the ethnographic object of inquiry in the following section and connect them to the challenges of ethnographically studying infrastructuring that derive from the dimensions of information infrastructure described in Section 2.

\subsection{Pursuing the phenomenon}

The challenges of studying information infrastructures are informed by discussions that occurred in anthropology in the 1960s regarding the concept of culture. Anthropologists realized that culture was neither static over time nor uniform within a given society, but instead was defined by changing dynamic temporal, conceptual, and spatial connections. Change was the constant and was expressed through everyday enactments and interpretations. Similarly, divisions within societies were not viewed as exceptions, which challenged assumptions of uniformity among members of a society in their lifeways, access to power, or the meanings they 
ascribed to things and activities. Increased "culture contact" contributed this shift in perspective as anthropologists witnessed dramatic change in some societies, leading them to ask how did things get to be as they are and through which discourses (sometimes contested) should the changes be understood. Empirical studies began to consider the historical underpinnings of and diversity in the practices of members of a society. This in turn required a greater emphasis in tracing the historical roots and contested understandings of the cultural experiences of members of a society.

These changes in views about culture, from a static and homogenous view of culture to one that sees culture as emergent and variable, have implications for the study of infrastructuring where infrastructures are understood to emerge over time through the diverse practices of those who engage with them. As with culture, the "object of inquiry" is not singular, nor stable, which requires new strategies for both following connections and allowing for emergence. This also suggests that peoples' relations to the always emerging and accreting infrastructures with which they engage is variable, offering no singular definition or view of information infrastructures from the perspective of those who engage with them. And while the vocabulary of people engaging with infrastructures is not the same as that of the researchers studying them, their experiences and perspectives provide researchers with resources to understand infrastructuring. As with all ethnographic research the use of a range of "methods", including observation, interviews, and document analysis (Blomberg and Burrell, 2007; Blomberg and Karasti, 2013), aids the researcher in teasing apart and making graspable the complex phenomenon of infrastructuring.

In a related way, the notion of constructing the field rests on a willingness to pursue the phenomenon of interest within an "empirical landscape" that is not fixed. Studies 'remain more ambivalent about relevant locations' and actually 'make it part of their goal to find out where interesting things might be going on' (Hine 2007, p. 661).

\subsubsection{Following connections and discovering discontinuities}

Strategies of following connections, associations and putative relationships are at the very heart of how anthropologists have come to understand the field(site) as more than a place. Marcus has put forward "tracking" approaches that include following strategically selected entities, including the person, the object, the metaphor, the story, the biography, or the conflict across sites (Marcus 1995, p. 105-110). And later, with concern for the changing sensibilities and intensities of ethnography, he emphasized the need to explore not only connections, but also parallels and contrasts among a variety of often seemingly incommensurate sites (Marcus 1998), along with movement in terms of displacements and juxtapositions (Marcus 2007).

Hine's connective ethnography of "systematics as cyberscience" is a good example of an approach that pursues the phenomenon under study by following connections (Hine 2008). By paying specific attention to the relations between online and offline activities the 'connections that seem to make sense in terms of understanding the practices and preoccupations of a particular phenomenon' are considered (ibid., p. 55) and by 'following strands of meaning-making across what may seem at first sight to be self-contained cultural domains' (ibid., p. 57) connections are recognized. Hine's reasoning about the field was guided by an understanding of cyberscience as 'a complex phenomenon inhabiting a range of sites and forms of expressions and time 
scales' (ibid., p. 51). In reflexively constructing the field, she was informed by the theoretical perspectives and methodological preferences of STS, and also by an appreciation that ' $[\mathrm{t}]$ he field site [...] is not a predetermined entity' (ibid., p. 54).

In reflecting on the "field" in the study of electronic patient records (EPR), Jensen (2010, p. 20) writes, 'the technology seemed neither singular, nor singularly attached to any one site. Rather it seemed distributed, and located in what I came to think of as a fractal landscape' where complexity is reproduced regardless of where one zooms in (Jensen 2007). The EPR system was continually being negotiated and revised as it moved to new locations or was taken up by different actors. In order to allow for the emergence of these multivalent states of being Jensen had to, 'empirically track down how technologies are constructed and transformed in multiple situations and networks and to analyze the specific consequences such constructions have for different practices and actors' (Jensen 2010, p. 21). The EPR study (Jensen 2007, 2010) and a more recent study of development aid (Jensen and Winthereik 2013) highlight infrastructures as "fractal landscapes", always emerging, so that we can 'assume neither their stability nor their ability to connect' in a straightforward manner (Jensen and Winthereik 2013, p. 12).

In this way the notion of constructing the field in anthropology is relevant to the study of emerging infrastructures that are not stable and whose existence is only partial. These 'peculiar objects of study require a kind of theoretical and methodological flexibility and attentiveness, which is all too easily diminished if one is certain about how to approach the object because one already knows what it is and does' (Jensen 2010, p. 20). This flexibility to follow the connections and also discover the disconnects is central to how the field is conceptualized in anthropology. The field emerges through the interactions of the researcher with the phenomena.

\subsubsection{Extending the field}

A number of approaches for extending the field have been proposed in the literature. We present examples from the literature on studying information infrastructure that offer different methodological strategies and approaches for extending (scaling) the field. We summarize by reflecting on how the methodological strengths and weaknesses of each varies in relation to assumptions about infrastructuring as empirical phenomena. These issues are not always straightforward and their applicability to infrastructuring should be considered in relation to the aims, analytical aspirations and theoretical underpinnings of the research.

Studies of large-scale infrastructures would be impossible if specific attention was not paid to issues of scaling from the single-site. One attempt to address the limits of the single-site are "scalar devices" that are an assembly of techniques, tools and representational conventions used by members themselves to know and manage scale (Ribes 2014). Scalar devices bypass the problem of the ethnographer defining the boundaries of the site by relying fundamentally on members' knowledge and understanding of the scaling of the infrastructure. The devices become observable through the tools that actors develop and use to define the reach of the infrastructure, such as surveys, descriptive statistics, benchmark statistics, meeting agendas, slides and notes (ibid.). 
A somewhat different strategy to address the issue of scaling is the "multiplication of sites" approach which assembles together several single-sited studies of homogeneously conceived conceptual units. One of the classic examples of this approach is Star and Ruhleder's study of an early cyberinfrastucture, the Worm Community System (WCS), developed for a community of biologists collaboratively studying a tiny nematode called "c.elegans" (Star and Ruhleder 1994, 1996). Beginning with the participating laboratories as the "sites" and assuming a kind of "on the same plane" similarity between the sites, the researchers chose 25 laboratories (out of the total of 120) where the discourse, work practices and material arrangements were observed and more than 100 biologists (out of 1400) were interviewed over a period of three years. At each field site of WCS implementation the researchers would get to know the people, their scientific interests and the arrangements of their lab, and how they were using the WCS. Carrying out ethnographic fieldwork at the sampled multiple sites allowed the scale to be extended while at the same time paying attention to concrete, situated practices (Star 2002).

The multiplication of sites approach is amended in the Biography of Artifact (BoA) approach where the selection of sites is strategic, theoretically informed ("strategic ethnography") and 'guided by a provisional understanding of the moments, locales, nexuses in which artefacts and attendant practices and knowledges were being created, exchanged, traded, and validated' (Pollock and Williams 2010, p. 544). The BoA approach was developed to study packaged software solutions in the context of enterprise infrastructures, such as Enterprise Resource Planning (ERP) systems. It expands the focus of research temporally and across different social settings and scales by 'addressing multiple moments and sites of innovation, and encompassing different phases of [...] the systems development cycle (design, selection/procurement, implementation and use), and the multiple such cycles that constitute the product cycle for a particular artefact' (ibid., p. 524). These strategically selected, multiple sites when taken together provide a view onto the longitudinal qualities of ERP system in a diversity of locales of development and product cycles/trajectories.

In contrast to a multiplication of sites approach which assumes that the studied phenomenon can be characterized by sampling enough sites to add details that when taken together characterizes the whole, a multi-sited approach suggests that there are a myriad of alternative ways of formulating the object of ethnographic study with no assumption about the totality or unity of the object. Multi-sited ethnography 'moves out from the single sites and local situations of conventional ethnographic research designs to examine the circulation of cultural meanings, objects, and identities in diffuse time-space' and it 'takes unexpected trajectories in tracing a cultural formation across and within multiple sites of activity' (Marcus 1995, 96). Multi-sited ethnography recognizes that there are variety of possibly transient and changing places, spaces, situations and encounters that can form the focus of a study. The ethnographer constructs the field through their engagement with it over the course of the study. Multi-sited ethnography broadens and diversifies the empirical field and the object of inquiry in order to address research problems that cannot be accounted for 'by remaining focused on a single site of intensive investigation' (ibid., p. 96). Multi-sited ethnography acknowledges that the field and the object of study 
cannot be known beforehand, nor the sampling strategy defined in advance as they emerge when the researcher actively connects different sites of investigation.

Multi-sited ethnography challenges the notion of site as a location. As Hine (2007, p. 660-661) notes, studies that begin from given notions of the sites do not capture the spirit of the multi-sited imaginary since 'these bounded cultural entities rarely exist, and it is a distraction to assume in advance that they can usefully define our studies'. Techniques for constructing the field in multi-sited ethnography are understood as 'practices of construction through (preplanned or opportunistic) movement and of tracing within different settings of a complex cultural phenomenon' (Marcus 1995, p. 106). Aligning with the methodological injunction to follow the human and/or nonhuman actors (Latour 1987) in STS, multi-sited research is committed to following 'people, connections, associations, and relationships across space (because they are substantially continuous but spatially non-contiguous)' (Falzon 2009, p. 1-2).

By emphasizing heterogeneity and multiplicity (Mol and Law 2002), rather than connections Vertesi (2014) directs our attention to the field as consisting of layers of multiple, coexisting and nonconforming infrastructures. She introduces the analytic vocabulary of "seams" for studying heterogeneous multi-infrastructural environments. Infrastructures often collide where their seams are visible in their many edges, endings and exclusions, and the members must bring the infrastructures together in locally accountable ways. The members can be seen to skillfully produce 'fleeting moments of alignment suited to particular tasks with materials ready-tohand' (Vertesi 2014, p. 268) as the connections between constituent infrastructures 'aren't connections because they aren't coherent and they aren't joined up into something consistent. Except that they are nevertheless brought together...' (Law 2004, p. 106).

By not assuming phenomena are stable and coherent, Jensen and Winthereik's advocate studying infrastructures as emerging, practical ontologies that are 'based on a fractal, recursive imagery of infrastructure' (2013, p. 9). Their approach, drawing on Strathern's post-plural (1992) and Latour's nonmodernist (1993) ethnography, characterizes infrastructures as emerging, 'rather wildly incoherent and only partly materialized' (ibid., p. 11), where their stability and ability to connect is not assumed, and where there are many competing "wholes" always in play. For Jensen and Winthereik "each site, "small" or "large", generates both knowledge and gaps of knowledge, as do the sites in combination. This imagery is fractal because it pictures the complexity of infrastructure as scale invariant, with complexity replicating across scales.' (ibid., p. 9) The researcher constructs the practical ontology together with the participants, which requires flexibility and attentiveness, as well as ongoing inclusion of informants in these processes.

We are suggesting that by taking a multi-sited and "practical ontologies" perspective a flexible and inclusive strategy is provided. While a multiplication of sites approach can be a useful way to begin to layout a fieldwork strategy for studying complex, extended phenomena, it is also important to consider how it may introduce limitations. For example, it may not be possible to find enough suitable and comparable units of analysis that are at the "same horizontal level" to include in the study. Similarly, Biography of Artefacts approach may not be applicable in cases 
where the development processes cannot be characterized as having evolutionary trajectories on which the approach is based. Lastly, a "scalar devices" technique, while it applies to situations where the participants have shared understanding of the 'bounded' information infrastructure entity, such as a cyberinfrastructure project, with its focus on members' tools to "manage" scale, non-trivial complexities of infrastructures may remain invisible to the members as well as the researcher.

\subsubsection{Reflexively bounding the field}

The willingness to pursue the phenomenon by following the relations necessitates decisions about bounding the field. According to Hine, 'it is not always possible to identify in advance where the relevant social dynamics for understanding a particular technology are going on' (Hine 2009, p. 4). A set of fieldwork boundaries is the outcome of an investigation rather than its precursor. One iconic example of this is a study of the Zimbabwe bush pump that highlights how technology is flexibly and variably defined. As such the boundaries of the associated fields vary. As described by de Laet and Mol (2000, p. 252),

'The Pump is a mechanical object, it is a hydraulic system, but it is also a device installed by the community, a health promoter and a nation-building apparatus. It has each of these identities - and each comes with its own different boundaries.'

Pursuing the phenomenon and bounding the field intertwine closely with the need for openness in where initial, sometimes seemingly obvious, boundaries are placed. Delineating the "object of inquiry" is an ongoing activity which requires deciding where, when and how to start, what avenues to pursue, and where, when and how to stop (Hine 2009, p. 2). This helps ensure that research questions are both coherently addressed and adapted to the empirical landscape that emerges. Also at issue are decisions about bounding the study in its reach and depth in other words, whether to pursue a particular set of connections outward, and whether to drill down to more depth in a particular place or event (ibid., p. 17). Making decisions about bounding the field necessitates attention also to other dimensions of the phenomenon, such as invisibility, emerging and partially existing infrastructures, and intervention.

Pursuing connections offers the possibility of crafting the object of inquiry to engage in a particular argument, or to be significant to an identified context of concern (Marcus 1998). Hine further reminds us of the practical limitations and partiality of "connective ethnography" suggesting that the "[c]onnections are simply too multiple and too diverse for any ethnographer to be able to claim to have covered a whole territory or to have found out in any absolute sense what constitutes a particular phenomenon.' (Hine 2008, p. 55) Working out methodologically these issues is also bound up with where one perceives a study should travel analytically (Hine 2009, p. 2).

Larkin (2013, p. 330) similarly argues that there are 'ever-proliferating networks that can be mobilized to understand infrastructures' which requires choice on the part of the researcher. Because infrastructures operate on different levels, often at the same time, choosing which level to focus on is guided by the analytic and intellectual concerns of the researcher. In turn this exposes epistemological and political commitments involved in what one sees as infrastructure and what is left out (ibid.). 
Law (2004) makes a related point, but from a methodological point of view. He starts from the proposition that methods in social science are constitutive, rather than reflective of social reality. Thus, according to Law, the researcher's agency should be considered as a constructor of reality. Law urges researchers to examine their methodological choices for the directions they push, the exclusions they create, and their relation to possible study contexts. Following from the proposition that methods are constitutive of, rather than reflective of social reality, we need to face up to the selective nature of methods which work not simply by detecting (and amplifying) a reality, but also by ignoring parts of a reality (ibid.). Through a notion of methods assemblage, i.e. enactments of relations that make some things (representations, objects, subjects, apprehensions) present "in-here", whilst making others absent "out-there" methods not only produce presences but also absences.

Method assemblages also put the researcher in the position of crafting and enacting boundaries between presence, manifest absence and Otherness (ibid.). The boundaries are necessary, each category depends on the others, and they cannot be avoided. To put it differently, there will always be Othering, as what is brought to presence or manifest absence is always limited and potentially contestable. In the context of constructing the field, Law's point suggests following the phenomenon by exploring its connections and by so doing becoming aware of the inevitable inclusions and exclusions created by the researcher. The fieldworker then must question takenfor-granted ideas about infrastructures, their technological components, and how actors are conceptualized in relation to them. The fieldworker must engage with situations as they unfold, and as such the field is reflexively and continually (re)defined.

The notion of constructing the field offers a nuanced approach to investigating information infrastructures, one that is inherently partial and one that aims to increase awareness of this partiality and the fieldworker's role in constructing the field.

\subsection{Inversing infrastructural relations}

Infrastructural inversion, initially introduced by Bowker (1994) and elaborated by Bowker and Star (1999), is a conceptually based notion with methodological consequences, which closely relates to our invisible dimension. Infrastructural inversion struggles against the tendency of infrastructure to 'disappear into the woodwork' (ibid., p. 34) by operating as a "gestalt switch", bringing to the foreground what typically remains in the background. Even with spectacular kinds of infrastructures designed for public display to elicit awe and admiration (Larkin 2013), parts of the infrastructure, such as those relating to the regular operations or maintenance and repair work may remain opaque or unknown. Star (1999, p. 379) reminds us,

'Study an information system and neglect its standards, wires, and settings, and you miss equally essential aspects of aesthetics, justice and change. Perhaps if we stopped thinking of computers as information highways and began to think of them more modestly as symbolic sewers, this realm would open up a bit.'

An integral issue is that 'short of breakdown, infrastructures tend to remain invisible at the level of use and experience' (Harvey et al. 2017, p. 3). This is a central problem for the empirical study of infrastructures and for notions of constructing the field 
specifically. Ethnographic approaches however are well suited to address the issue of invisibility as they employ a range of methods and take care to examine the phenomenon of interest from multiple perspectives (Blomberg and Burrell, 2007). This triangulation of methods (i.e. interviews, observation and document analysis) and/or points of view (i.e. people differently positioned with respect to the phenomenon) can contribute to rendering aspects of infrastructure that are invisible to some actors or difficult to "see" using certain methods more discernible.

Infrastructural inversion encourages attentiveness to information infrastructure via an analytical entry-point of focus on materiality, mundane operational processes and invisible, unnoticed work. It rallies attention to the investigation of "singularly unexciting" things, such as "boring" lists, mundane plugs, technical specifications, standards, bureaucratic forms and details buried in inaccessible code, as well as hidden mechanisms subtending the more visible processes, foregrounding their manifold relations (Star 1999). It steers a focus on the activities and work practices that warrant the functioning of infrastructure, rather than those that it invisibly supports. It shifts interest by de-centering the artifacts and tools with which users interact to focus on the infrastructural work that builds and sustains them. In other words, it shifts 'the emphasis from changes in infrastructural components to changes in infrastructural relations' (Bowker et al. 2010, p. 99). Thus, inversion allows recognition of the depths of interdependence of technical, socio-organizational and institutional components that are involved in the infrastructure development (Mongili and Pellegrino 2014).

The notion of infrastructural inversion acknowledges that while it takes a lot of work to render infrastructures as taken-for-granted and invisible, it also takes a lot of work to "invert" the infrastructure in its myriad relations. A definitely good beginning is careful ethnographic study that attends to production, coordination and articulation work; and workarounds and backstage activities; surfacing many kinds of invisible work (Suchman 1995; Blomberg et al. 1996; Star 1999; Star and Strauss 1999; Nardi and Engeström 1999), and identifying the reified invisible work inscribed in traces 'left behind by coders, designers and users of systems' (Star 1999, p. 385).

In the following we present three strategies for attending to the invisible, as in "taken for granted", "out of the everyday experience of use" or "out of sight", aspects of infrastructuring. By investigating moments of breakdown, following how members themselves engage in activities of infrastructural inversion, and following infrastructural traces in the material and technical environments, ethnographic fieldwork can achieve aspects of infrastructural inversion.

One entry point for infrastructural inversion is breakdowns (Bowker and Star 1999), where the normally invisible quality of working infrastructure becomes visible when it breaks' (Star and Ruhleder 1996, p. 115). Focusing on breakdowns draws on the early work of Garfinkel (1967) where he proposed "breaching experiments" where informal, unwritten rules were intentionally broken exposing their logic. A related variation to studying breakdowns are "controversy studies" in STS where controversies uncover underlying expectations and turf battles that undergird seemingly "objective" technology development. The invisible work that keeps the 
infrastructure aligned becomes accessible to the researcher as actors provide explicit articulations of the controversy (Ribes and Lee 2010).

In a study of an electronic medication module upgrade, Bossen and Markussen (2010) show how the introduction of the new version created a breakdown that required a temporary return to the older system. This breakdown created an inversion that brought to the fore the work that actors and artifacts do to achieve stable cooperative arrangements. Relatedly, in a study of distributed network of sensing devices by Mayernik et al. (2013), the initial incompatibilities between sensors and networking equipment caused breakdowns that when "unearthed" enabled an alternative configuration with a re-focus on manual data collection and sampling practices. On occasions such as these where naturally occurring breakdowns occur, activities of infrastructuring are made visible through infrastructural inversion (Ribes and Lee 2010).

Another entry point for carrying out infrastructural inversion in ethnographic studies is turning to those members who already are involved in such activities as part of their job descriptions (Kaltenbrunner 2015; Dagiral and Peerbaye 2016; Parmiggiani et al. 2015; Parmiggiani and Monteiro 2016). In the case of information infrastructures these people are often designers or others in roles related to designing or maintaining aspects of the infrastructure. In a study of infrastructure development in an oil and gas company, Parmiggiani identified a 'subset of actors who, as part of their daily work, were in charge of answering the same questions I had to answer as part of my research' (2015, p. 75). She followed these "infrastructural allies" (Beaulieu 2010) who were engaged in the process of aligning the evolving environmental monitoring infrastructure with the significant installed base of existing tools, work practices and professional roles and responsibilities. By so doing she was able to detail significant infrastructural activities in support of the emerging infrastructure (Parmiggiani 2015).

A third entry point for performing infrastructural inversion explores and inverts aspects of the accreted material environment. This is based on the idea that people produce documents and other material traces to know their communities and to act within them. Documentary practices are constitutive of distributed, large-scale collaboration, as exemplified by for example trading records in global financial markets (Knorr-Cetina and Bruegger 2002) and standards and protocols that guide diagnosis work in healthcare (Bowker and Star 1999). Furthermore, technologically mediated environments produce high volumes of their own kinds of digital inscriptions and traces, including various types of logs, version histories, conversation transcripts and source code. "Trace ethnography" has been proposed as a method through which these often "thin" digital traces are inverted and used in combination to "provide rich qualitative insights into the interactions of users, allowing [...] to retroactively reconstruct specific actions at a fine level of granularity' (Geiger and Ribes 2011, p. 1). Trace ethnography reveals often the invisible infrastructure that underlie routinized activities, allowing researchers to generate highly empirical accounts of network-level phenomena without researchers having to visit every node (ibid.). 
The notion of infrastructural inversion in the ethnographic study of infrastructuring is particularly important for orienting and directing attention to the invisible dimension of information infrastructures. The original formulation by Bowker (1994) considered it an analyst's task to bring light to infrastructural invisibilities. While this remains an important direction, new developments also advocate the possibility of including study participants in inverting infrastructural relations. This is what we see more widely through studies in which participants portraying various intentionalities engage in tinkering, designing, hacking or vandalizing their systems (Geiger and Ribes 2010; Kaltenbrunner 2015; Korn and Voida 2015; Wagenknecht and Korn 2016), decentering the emphasis on infrastructural inversion as an analytic notion towards inversion as an "empirical condition" and suggesting that 'some situations elicit naturally occurring inversions' (Harvey et al. 2017, p. 4).

\section{Discussion}

There have been vocal critiques of so-called "localist studies" in the CSCW literature (e.g. Pollock and Williams 2010; Monteiro et al. 2013), often defined as small scale and short-term studies restricted to particular settings and timeframes. While we agree with the need for ethnographic studies that engage beyond a single-site for the investigation of infrastructures (Karasti et al. 2010; Blomberg and Karasti 2013), we also stress that localization still needs to be taken seriously.

Furthermore, we argue that in many ways we are just beginning to be in a position to do theoretically informed ethnographic research on infrastructures as promoted by Pollock and Williams (2010). What we need more of are empirical studies of infrastructuring that acknowledge the role of the researcher in constructing the field and that reflect an openness and curiosity for exploring new ways of conceptualizing infrastructuring. In addition, we emphasize that in seeking alternatives we need to base our explorations on the new advances in ethnography that problematize the field as the site of inquiry. Notions of constructing the field provide new ways that ethnography can shape how we understand information infrastructures by understanding them through the lens of infrastructuring. As we have shown in the previous sections there have been significant developments in ethnographic research since Star and Ruhleder's influential study, which address some of the concerns with normative views of ethnographic research where the field is unproblematically assumed and where notions of holism cloud our understanding of diversity and change as steadfast characteristics of human societies.

Furthermore, we argue that the notion of constructing the field, where the researcher reflexively delineates the object of inquiry is a methodological foundation for empirically studying complex, extended phenomena, such as information infrastructures. With a scarcity of methodological research on how to study information infrastructures there is still a need to specify how even the most obvious analytic tools such as extended temporal, spatial, technological, organizational, institutional and political/ethical framings can be practically and empirically achieved.

By deliberating on the value of combining the notion of constructing the field with reflection on some of the defining dimensions of information infrastructures outlined 
above we now take up a discussion of the implications this has for design oriented studies of information infrastructures.

\subsection{On assumptions of information infrastructures}

Information system design fields often start their investigations of information infrastructures with a particular interest in conceptualizing the phenomenon as an "object" or "artifact" (e.g. Tilson et al. 2010). This stance is based on a basic assumption that information infrastructures are bounded entities ("objects") for which their components can be defined. An incisive description of the situation in Information Systems (IS) research is given in the editorial to the special issue on Innovation in Information Infrastructure (Monteiro et al. 2014) that flags two shifts that have occurred in the study of information infrastructures. The first shift addressed the 'ways in which infrastructure building initiatives needed to simultaneously address multiple locales, phases and timescales-both the "here and now" and the longer-term evolution of the system' (ibid. 2014, p. iii). And the second was a shift from 'characterizing infrastructures as objects (noun) toward a more processual focus' on infrastructuring (verb) that addresses the practices of building (designing, implementing, using, further developing) infrastructures (ibid.).

The recent move to focus on infrastructuring as processual has continued the blurring of the boundaries between design, implementation and use for instance in Participatory Design as reviewed by Karasti (2014). The design object has broadened from mere technical products towards embedded socio-technical constellations where the types of infrastructure interventions have diversified (e.g. Karasti and Syrjänen 2004; Pipek and Wulf 2009; Hillgren et al. 2011; Björgvinsson et al. 2012; Le Dantec and DiSalvo 2013). The continuing focus however is primarily on designoriented intentionalities with particular interest in the longitudinally extended processes of infrastructuring that bear resemblance to our dimension of emerging and accreting. Others have chosen intentionalities to radically challenge the existing installed base and to create alternatives (e.g. Clement et al. 2012; Björgvinsson 2014). Although a departure from a majority of research on information infrastructures as objects in system design, the processual focus on the activities of infrastructuring leaves ambiguous the nature, dimensions and scopes of infrastructures (Karasti 2014).

The Biography of Artefacts (BoA) approach provides another perspective on systems design oriented investigation and development of infrastructures. It is based on assumptions about the systems development lifecycle (design, selection/procurement, implementation and use) that constitute different phases of the product cycle for a particular artifact (Pollock and Williams 2010). From the perspective of BoA there is a trajectory in the evolution of an information infrastructure, which suggests an inherent directionality in the development of information infrastructures (Jensen and Winthereik 2013). BoA can lead to a view that information infrastructures progress in an evolutionary fashion, which can foreclose other alternatives that are more unpredictable, emergent, uneven, inconsistent in their trajectory. It may also lead to a preference for the "master narrative", which Star (1999) raised as methodological concern. 
While the BoA perspective acknowledges that in the early stages of infrastructure development 'processes may be relatively open' (Pollock and Williams 2010, p. 546), it 'still assumes a certain degree of coherence, stability and materialization of the infrastructure' (Jensen and Winthereik 2013, p. 11). From this perspective stability and coherence is required to recognize particular socio-technical assemblage as infrastructure. However, in many cases of what we might call infrastructuring there are no "biographies" or "trajectories" to be followed, as in case of infrastructures for development aid (ibid.), or the many cases of "knowledge infrastructures", a.k.a cyberinfrastructures or research infrastructures (Edwards et al. 2013; Karasti et al. 2016a, 2016b). The infrastructure may be emergent (expansive and open-ended), and also wrought with uncertainty, thus making the object of inquiry vague and challenging to delineate if stable or taken-for-granted paths cannot be assumed (Jensen and Winthereik 2013, p. 12). Jensen argues 'that by letting go of both a priori conceptions of what technologies really are and deterministic understandings of what they must turn into, facilitates the study of partially existing objects' (Jensen 2010, p. 26).

Infrastructures are continuously emerging with accreting elements bound together yet rarely fully cohering and yet we are lured into seeing them as stable, robust and bounded. Infrastructures are at times fragile and at others enduring. Sometimes they are viewed as coherent objects, at other times best viewed as heterogeneous, fractal, recursive (Jensen and Winthereik 2013), or even nothing at all (Jackson and Buyuktur 2014). Research on infrastructuring must therefore be attuned to the chameleon quality of infrastructures where they can change with the politics of their past, present and future condition.

Contemporary ethnography of infrastructure thus needs to be able to address continuity and change - the stable and emerging forms of infrastructures, all the while keeping relevant both variability and consistency. The view of a field of study that is always being constructed and where the object of inquiry is delineated through ongoing engagement provides the openness required to investigate information infrastructures through the lens of infrastructuring. Contrary to the position espoused by some that ethnography is too focused on local and bounded sites, we suggest ethnography is exactly what is needed to grasp the dynamic complexity and open-endedness of information infrastructures.

\subsection{On extent, emergence and partiality}

Star and colleagues initial work recognized scaling, particularly spatial scaling, as a challenge for ethnography (Star 1999). Star and Ruhleder (1994, 1996), addressed the scaling issue by multiplying the sites of ethnographic investigation. They sampled sites from among those research laboratories participating in the Worm Community System. Given this bounded set of laboratories, they assembled a horizontal set of homogenously conceived conceptual units as their ethnographic field. In comparison to Star and Ruhleder $(1994,1996)$, Pollock and Williams (2010) address the scaling issue by selecting theoretically-informed research sites that cover the trajectory of the development and product lifecycles, while recognizing that choices are '... also necessarily influenced by opportunism and pragmatic exigencies' (ibid., p. 532). While unanticipated forces necessarily shape the research path, they are to be managed within the construct of the initial strategic research plan. 
Our perspective however views (un)foreseen opportunities and practical constraints as essential "materials" out of which the field is continually delineating. Our caution here is that there is a risk in "nailing down" too firmly the sampling strategy in advance as some of the openness to the unanticipated will be foreclosed limiting the researcher's engagement with the phenomenon. The notion of constructing the field instead is founded on the idea that fieldwork choices are continually being made as the phenomenon is pursued. It is during fieldwork that the strategic relevance of location can be understood which requires an openness and sensitivity towards the phenomenon studied. This is recognized in examples from Marcus' multi-sited (Marcus 1995, 1998), Hine's connective (Hine 2008), Vertesi's seamful (Vertesi 2014) and Jensen and Winthereik's fractal, recursive (Jensen 2010; Jensen and Winthereik 2013) views on the field of study as constructed.

Scaling also requires attention to broad institutional contexts and policy levels (Ribes and Finholt 2009; Williams and Pollock 2010; Monteiro et al. 2013; Ribes 2014; Jackson et al. 2013, 2014; Karasti et al. 2016a, 2016b; Kaltenbrunner 2017), which often have been overlooked in more development-oriented conceptions of information infrastructures prevalent in design fields. We argue that the integration of broader institutional contexts requires ethnographies that more attentively follow the phenomenon under study, and take an interest in pursuing it over and across a variety of scopes and boundaries. The institutions that enable, constrain and facilitate the evolution of infrastructures, such as government agencies, funding agencies, and standards bodies, are legitimate sites of inquiry. "Scaling strategies" would do well to be open to these as sites of significant infrastructuring work, including infrastructure design.

Approaches that extend the field have differing assumptions about whether their object of inquiry can be investigated as a clearly defined "whole". Multiplication of sites strategies build on 'the assumption that infrastructures can in principle be comprehensively characterized by adding together enough detail from enough sites' (Jensen and Winthreik 2013, p. 9). However as Strathern explains for any analytical endeavor, 'the perception and filling in of a gap lead to awareness of the gaps' (Strathern 1989, p. 63). The problem is that the more empirical or analytical "gaps" are filled in the more other gaps are made visible. A strategy of including multiple sites can never "add up" to a whole, nor will it necessarily create a more comprehensive or complete picture (Jensen and Winthereik 2013, p. 9). Likewise, researchers who assume that infrastructures 'operate by linking together many different organizational and interorganizational levels' are 'invariably led to posit some kind of coherent infrastructural whole' (ibid., p. 11).

Multi-sited, connective, seamful and fractal approaches, on the other hand, dispense with the assumption that ethnography must be premised on, or work to capture, a "whole picture" of an infrastructure. Infrastructures are more usefully viewed as inthe-making, emerging, recursive. As objects of inquiry they only partially exist, necessitating ongoing methodological flexibility and attentiveness (Jensen 2010). Pursuing the phenomenon by following the connections and allowing for emergence are ethnographic strategies that assume partiality, not relying on completeness or 
adherence on a priori delineation of the object of inquiry (Hine 2008). While perhaps disquieting for some, infrastructures only can be grasped partially.

The notion of constructing the field offers a way of studying infrastructures through a lens of infrastructuring that does not aspire to a total depiction of the "whole" phenomenon, rather it aims to increase awareness of this partiality which in turn requires that the researcher accepts responsibility for reflexively defining the always emerging field and object of inquiry. The constructed character of the field highlights the researchers' active, reflexive agency in determining the focus of study (Marcus 1998; Hine 2007).

\subsection{On intervention in infrastructuring}

One of the strengths of ethnography is that it offers opportunities 'for interacting and engaging with the field studied' (Pors et al. 2002, p. 4). '[E]thnographically inspired research inevitably intervenes in the fields studied' (ibid., p. 5, italics original). Furthermore, the "field" does not present itself as a pre-given object of inquiry that is simply entered, but rather emerges during the process of ethnographic engagement with the phenomenon. Intervening in the field is not something the researcher can choose to do or not to do, but is an unavoidable condition of ethnographic research (Henriksen 2002). The notion of constructing the field highlights this in the sense that "studying and describing" the field is interwoven with "intervening and changing" it rather than separate practices.

Information infrastructures are increasingly understood as complex, uncertain and always becoming where actors contribute their ideas and aspirations, negotiate agendas and strategies, and influence each other in order to achieve multiple and sometimes conflicting purposes and goals. This view posits the active construction of "partially existing objects" where the ethnographer constructs the field together with other participants. In this way the ethnographer 'participates with other actors (but of course with different means and aims) in what might be called experiments to articulate and specify the existence of things, and to engage and articulate the consequences of specific reality constructions' (Jensen 2010, p. 21). Recognizing that multiple intentionalities and interventions are involved in infrastructuring, Jensen and Winthereik (2013, p. 29) introduce the notion of "practical ontology" that is at once a description of the work done in the world by heterogeneous actors (such as the many people, technologies and organizations engaged in monitoring) and a description of the work done by the researchers aiming to elicit that work.'

While there is no consensual definition of what it means to "intervene", we need to decenter design and recognize the tension between planned and emergent change in infrastructures. Combined with a realization that the ethnographic field is always constructed this opens the possibility for the exploration of a variety of intentionalities and interventions possible in infrastructuring (e.g. Björgvinsson et al. 2010; Le Dantec and DiSalvo 2013; Menendez-Blanco et al. 2017).

\section{Conclusions}

The study of information infrastructures is enhanced by broadening the researchers' toolbox so as not to limit the scope of investigation to those that are spatially, 
temporally and organizationally circumscribed a priori. We need terms that portray infrastructure as expansive and open-ended with a fundamentally equivocal ontology (Winthereik and Verran 2012). An openness to pursuing the phenomenon wherever it leads is supported by the view that the field is constructed by the engagement of the researcher with the phenomenon of study and in the process the object of inquiry delineated if only for the moment. When we abandon assumptions about infrastructural stability, boundedness and coherence, we create new possibilities for how to study information infrastructures. The accustomed roles of designers, researchers and users become more fluid and blurred when we expand our understandings of intentionality and intervention and engage infrastructures directly and reflexively.

By taking responsibility for reflexively constructing the field and delineating the object of inquiry the many forms of infrastructuring can become the purview of empirical study. We believe insights derived from understanding the field as constructed, along with new developments in the ethnographic study of complex and extended phenomena, can come together to help us explore the ontology of infrastructures. The dimensions of information infrastructures, that we have outlined, manifest themselves in different ways, to different degrees and in hybrid combinations. The ethnographic investigation of infrastructuring, including inverting infrastructural relations, following connections, discovering discontinuities, and extending and reflexively bounding the field, can be guided by attention to these dimensions that inform the ontologies of infrastructures.

We offer that socially and politically motivated research designs can be advanced by understanding the way the field is constructed reflexively and the object of inquiry is continually being delineated through engagement with the phenomenon. Theorizing about studying infrastructuring ethnographically foregrounds issues of ethics, politics and responsibility. Finally, thoughtful attention to constructing the field as a central methodological consideration gives rise to creative designs of information infrastructures that address contemporary challenges of increasingly connected and yet fragmented environments.

\section{Acknowledgements}

Karasti acknowledges the funding by Velux Visiting Professor Program of Villum Foundation and the generosity of Prof. Jesper Simonsen that made possible to work on this article as Guest Professor at the Department of People and Technology, Roskilde University, Denmark during 2015-2016. In addition, Karasti acknowledges Academy of Finland funded research project 'Multi-scoped Infrastructuring' \#285903 that has provided support for finalizing the article in 2016-2017. Blomberg acknowledges the support of IBM Research, particularly the Cloud and Mobile Enterprise Research group, for allowing her time to work on this article.

\section{Notes}

${ }^{1}$ Star and Ruhleder identified eight characteristics of information infrastructure in (Star and Ruhleder 1996, p. 112-113) and a ninth was added in (Star 1999, p. 382; 
Bowker and Star 1999, p. 35). The nine characteristics are (1) embeddedness, (2) transparency, (3) reach or scope, (4) learned as part of membership, (5) links with conventions of practice, (6) embodiment of standards, (7) built on an installed base, (8) becomes visible upon breakdown, and (9) is fixed in modular increments, not all at once or globally. While there is no one-to-one or single mapping of these characteristics to our five dimensions, we see connections between our dimensions and Star and colleagues' characteristics: our relational most closely related to $(1,5$, $7)$, invisible to $(2,4,8)$, connected to $(3,6)$, emerging and accreting to $(7,9)$, and intervention and intentionality to $(7,9)$.

\section{References}

Adey, Peter; David Bissell; Kevin Hannam; Peter Merriman; and Mimi Sheller (eds.) (2014). The Routledge Handbook of Mobilities. London: Routledge.

Amit, Vered (ed.) (2000). Constructing the field: Ethnographic fieldwork in the contemporary world. London: Routledge.

Anand, Nikhil (2015). Accretion. Fieldsights - Theorizing the Contemporary, Cultural Anthropology Online, 24 September. http://www.culanth.org/fieldsights/715accretion. Accessed 16 December 2015.

Appadurai, Arjun (2014). Foreword. In Stephen Graham; and Colin McFarlane (eds.): Infrastructural lives: Urban infrastructure in context. Oxford, UK: Routledge, pp. xiixiii.

Appel, Hannah; Nikhil Anand; and Akhil Gupta (2015). Introduction: The Infrastructure Toolbox. Fieldsights - Theorizing the Contemporary, Cultural Anthropology Online, 24 September. http://www.culanth.org/fieldsights/714introduction-the-infrastructure-toolbox. Accessed 16 December 2015.

Barry, Andrew (2015). Discussion: Infrastructural Times. Fieldsights - Theorizing the Contemporary, Cultural Anthropology Online, September 24, 2015, http://www.culanth.org/fieldsights/724-discussion-infrastructural-times. Accessed 16 December 2015.

Beaulieu, Anne (2010). From co-location to co-presence: Shifts in the use of ethnography for the study of knowledge. Social Studies of Science, vol. 40, no. 5, pp. 453-470.

Björgvinsson, Erling (2014). The Making of Cultural Commons: Nasty Old Film Distribution and Funding. In Pelle Ehn; Elisabet M. Nilsson; and Richard Topgaard (eds.): Marginal Notes on Innovation, Design, and Democracy. Cambridge, MA: The MIT Press, pp. 187-225.

Bjögvinsson, Erling; Pelle Ehn; and Per-Anders Hillgren (2012). Design things and design thinking: Contemporary participatory design challenges. Design Issues, vol. 28, no. 3, pp. 101-116.

Bjögvinsson, Erling; Pelle Ehn; and Per-Anders Hillgren (2010). Participatory design and "democratizing innovation". In PDC2010: Proceedings of the 11th Participatory Design Conference, Sydney, Australia, 29 November - 3 December 2010. New York: ACM Press, pp. 41-50.

Blomberg, Jeanette; and Mark Burrell (2007). An ethnographic approach to design. In Julie Jacko and Andrew Sears (eds.): Human Computer Interaction Handbook: Fundamental, Evolving Technologies and Emerging Applications. Hillsdale, NJ: Lawrence Erlbaum Associates, pp. 965-988. 
Blomberg, Jeanette; and Helena Karasti (2013). Reflections on 25 years of ethnography in CSCW. Computer Supported Cooperative Work (CSCW), vol. 22, no. 4-6, pp. 373-423.

Blomberg, Jeanette; Lucy Suchman; and Randy H. Trigg (1996). Reflections on a Work-Oriented Design Project. Human-Computer Interaction, vol. 11, pp. 237-265.

Bossen, Claus; and Randi Markussen (2010). Infrastructuring and ordering devices in health care: Medication plans and practices on a hospital ward. Computer Supported Cooperative Work (CSCW), vol. 19, no. 6, pp. 615- 637.

Bowker, Geoffrey C. (1994). Science on the run: Information management and industrial geophysics at Schlumberger, 1920-1940. Cambridge, MA: MIT Press.

Bowker, Geoffrey C.; Karen Baker; Florence Millerand; and David Ribes (2010). Toward information infrastructure studies: Ways of knowing in a networked environment. In Jeremy Hunsinger; Lisbeth Klastrup; and Matthew M. Allen (eds.): International Handbook of Internet Research. Heidelberg, DE: Springer, pp. 97-117.

Bowker, Geoffrey C.; and Susan L. Star (1999). Sorting Things Out: Classification and Its Consequences. Cambridge, MA: MIT Press.

Büscher, Monika; John Urry; and Katian Witchger (eds.) (2011). Mobile Methods. Routledge: New York.

Ciborra, Claudio (ed.) (2000). From Control to Drift: The Dynamics of Corporate Information Infrastructures. Oxford University Press.

Clarke, Adele E.; and Susan L. Star (2008). The social world framework: A theory/methods package. In Edward J. Hackett; Olga Amsterdamska; Michael E. Lynch; and Judy Wajcman (eds.): The Handbook of Science and Technology Studies. Cambridge, MA: MIT Press, pp. 113-137.

Clement, Andrew; Brenda McPhail; Karen Louise Smith; and Joseph Ferenbok (2012). Probing, mocking and prototyping: Participatory approaches to identity infrastructuring. In PDC2012: Proceedings of the 12th Participatory Design Conference, Roskilde, Denmark, 12 - 16 August 2012. New York: ACM Press, pp. 2130.

Dagiral, Éric; and Ashveen Peerbaye (2016). Making Knowledge in Boundary Infrastructures: Inside and Beyond a Database for Rare Diseases. Science \& Technology Studies, vol. 29, no. 2, pp. 44-61.

Dalsgaard, Steffen; and Morten Nielsen (2013). Introduction: Time and the Field. Social Analysis, vol. 57, no. 1, pp. 1-19.

De Laet, Marianne; and Annemarie Mol (2000). The Zimbabwe Bush Pump: Mechanics of a Fluid Technology. Social Studies of Science, vol. 30, no. 2, pp. 225263.

Edwards, Paul N.; Steven J. Jackson; Geoffrey C. Bowker; and Cory P. Knobel (2007). Understanding infrastructure: Dynamics, tensions, and design. Final report of the workshop History and Theory of Infrastructure: Lessons for New Scientific Cyberinfrastructures. NSF, Office of Cyberinfrastructure. http://hdl.handle.net/2027.42/49353. Accessed 16 December 2015.

Edwards, Paul N.; Geoffrey C. Bowker; Steven J. Jackson; and Robin Williams (2009). Introduction: An agenda for infrastructure studies. Journal of the Association for Information Systems, vol. 10, no. 5, pp. 364-374.

Edwards, Paul N.; Steven J. Jackson; Melissa K. Chalmers; Geoffrey C. Bowker; Christine L. Borgman; David Ribes; Matt Burton; and Scout Calvert (2013). Knowledge Infrastructures: Intellectual Frameworks and Research Challenges. Ann 
Arbor: Deep Blue. http://knowledgeinfrastructures.org/. Accessed 16 December 2015.

Ehn, Pelle (2008). Participation in Design Things. In PDC2008: Proceedings of the 10th Participatory Design Conference, Bloomington, IN, USA, 30 September - 04 October 2008. New York: ACM Press, pp. 92-101.

Falzon, Mark-Anthony (2009). Introduction. In Falzon, Mark-Anthony (ed.) Multi-sited Ethnography: Theory, Praxis and Locality in Contemporary Research. Surrey, England: Ashgate, pp. 1-23.

Garfinkel, Harold (1967). Studies in ethnomethodology. New Jersey: Prentice-Hall.

Geiger, R. Stuart; and David Ribes (2010). The Work of Sustaining Order in Wikipedia: The Banning of a Vandal. In CSCW2010: Proceedings of the 2010 ACM Conference on Computer Supported Cooperative Work, Savannah, GA, USA, 06 - 10 February 2010. New York: ACM Press, pp. 117-126.

Geiger, R. Stuart; and David Ribes (2011). Trace ethnography: Following coordination through documentary practices. In HICSS44: Proceedings of the 44th Annual Hawaii International Conference on Systems Sciences, Kauai, HI, USA, 04 - 07 Jan 2011. Los Alamitos, CA: IEEE Press.

Gupta, Akhil; and James Ferguson (eds.) (1997). Anthropological Locations: Boundaries and Grounds of a Field Science. Berkeley, Los Angeles, London: University of California Press.

Hanseth, Olle (2010). From Systems and Tools to Networks and Infrastructures From Design to Cultivation. In Jonny Holmström; Mikael Viberg; and Andreas Lund (ed.): Industrial Informatics: Design, Use and Innovation. IGI Global, pp. 122-156.

Harvey, Penelope; Casper Bruun Jensen; and Atsuro Morita (eds.) (2017). Infrastructures and Social Complexity. A Companion. New York: Routledge.

Heidegger, Martin (1962). Being and Time. New York: Harper. Originally published in 1927.

Henriksen, Dixi Louise (2002). Locating virtual field sites and a dispersed object of research. Scandinavian Journal of Information Systems, vol. 14, no. 2, pp. 31-45.

Hillgren, Per-Anders; Anna Seravalli; and Anders Emilson (2011). Prototyping and infrastructuring in design for social innovation. CoDesign, vol. 7, no. 3-4, pp. 169183.

Hine, Christine (2007). Multi-sited Ethnography as a Middle Range Methodology for Contemporary STS. Science, Technology \& Human Values, vol. 32, no. 6, pp. 652671.

Hine, Christine (2008). Systematics as Cyberscience. Computers, Change, and Continuity in Science. Cambridge, London: The MIT Press.

Hine, Christine (2009). How can qualitative Internet researcher define the boundaries of their projects? In Annette N. Markham; and Nancy K. Baym (eds.): Internet inquiry: conversations about method. Thousand Oaks, CA: Sage Publications, pp. 120.

Jackson, Steven J. (2014). Rethinking Repair, in Tarleton Gillespie; Pablo J. Boczkowski; and Kirsten A. Foot (eds.) Media Technologies: Essays on Communication, Materiality and Society. Cambridge, MA: MIT Press, pp. 221-307.

Jackson, Steven J. (2015). Repair. Fieldsights - Theorizing the Contemporary, Cultural Anthropology Online, September 24, 2015, http://www.culanth.org/fieldsights/720-repair. Accessed 16 December 2015. 
Jackson, Steven J.; and Ayse Buyuktur (2014). Who Killed WATERS? Mess, Method, and Forensic Explanation in the Making and Unmaking of Large-scale Science Networks. Science Technology Human Values, vol. 39, no. 2, pp. 285-308.

Jackson, Steven J.; Tarleton Gillespie; and Sandra Payette (2014). The Policy Knot: Reintegrating Policy, Practice and Design in CSCW Studies of Social Computing. In CSCW2014: Proceedings of the 17th Computer Supported Cooperative Work Conference, Baltimore, MD, USA, 15 - 19 February 2014. New York: ACM Press, pp. 588-602.

Jackson, Steven J.; Stephanie Steinhardt; and Ayse Buyuktur (2013). Why CSCW needs science policy (and vice-versa). In CSCW2013: Proceedings of the 16th ComputerSupported Cooperative Work Conference, San Antonio, TX, USA, 23 - 27 February 2013. New York: ACM Press, pp. 1113-1124.

Jensen, Casper Bruun (2007) Infrastructural fractals: Revisiting the micro - macro distinction in social theory. Environment and Planning D: Society and Space, vol. 25, pp. 832-850.

Jensen, Casper Bruun (2010). Ontologies for developing things: Making health care futures through technology. Rotterdam: Sense Publishers.

Jensen, Casper Bruun; and Britt Ross Winthereik (2013). Monitoring Movements in Development Aid: Recursive Partnerships and Infrastructures. Cambridge, MA: The MIT Press.

Kaltenbrunner, Wolfgang (2015). Infrastructural inversion as a generative resource in digital scholarship. Science as Culture, vol. 24, no. 1, pp. 1-23.

Kaltenbrunner, Wolfgang (2017). Digital Infrastructure for the Humanities in Europe and the US: Governing Scholarship through Coordinated Tool Development. Computer Supported Cooperative Work (CSCW), vol. 26, no. 3, pp. 275-308.

Karasti, Helena (2014). Infrastructuring in participatory design. In $P D C^{\prime} 14$ : Proceedings of the 13th Conference on Participatory Design, Windhoek, Namibia, 06 - 10 October 2014. New York: ACM Press, pp. 141-150.

Karasti, Helena; and Karen Baker (2004). Infrastructuring for the long-term: Ecological information management. In HICSS37: Proceedings of the Hawaii International Conference on System Sciences, Big Island, HI, 5 - 8 Jan 2004. Los Alamitos, CA: IEEE Press.

Karasti, Helena; and Karen S. Baker (2008). Community Design: Growing One's Own Information Infrastructure. In PDC2008: Proceedings of the 10th Participatory Design Conference, Bloomington, IN, USA, 30 September - 04 October 2008. New York: ACM Press, pp. 217-220.

Karasti, Helena; and Anna-Liisa Syrjänen (2004). Artful infrastructuring in two cases of community PD. In PDC2004: Proceedings of the Eighth Participatory Design Conference, Toronto, Ontario, Canada, 27 - 31 July 2004. New York: ACM Press, pp. 20-30.

Karasti, Helena; Karen S. Baker; and Eija Halkola (2006). Enriching the Notion of Data Curation in e-Science: Data Managing and Information Infrastructuring in the Long Term Ecological Research (LTER) Network. Computer Supported Cooperative Work (CSCW), vol. 15, no. 4, pp. 321-358.

Karasti, Helena; Karen S. Baker; and Florence Millerand (2010). Infrastructure Time: Long-Term Matters in Collaborative Development. Computer Supported Cooperative Work (CSCW), vol. 19, no. 3-4, pp. 377-415. 
Karasti, Helena; Florence Millerand; Christine M. Hine; and Geoffrey C. Bowker (2016a). Knowledge Infrastructures: Part I. Science \& Technology Studies, vol. 29, no. 1 , pp. 2-12.

Karasti, Helena; Florence Millerand; Christine M. Hine; and Geoffrey C. Bowker (2016b). Knowledge Infrastructures: Part IV. Science \& Technology Studies, vol. 29, no. 4, pp. 2-9.

Kee, Kerk; F. and Larry D. Browning (2010). The dialectical tensions in the funding infrastructure of cyberinfrastructure. Computer Supported Cooperative Work (CSCW), vol. 19, no. 3, pp. 283-308.

Knorr-Cetina, Karin D.; and Urs Bruegger (2002). Global Microstructures: The Virtual Societies of Financial Markets. American Journal of Sociology, vol. 107, no. 4, pp. 905-950.

Korn, Matthias and Amy Voida (2015). Creating friction: Infrastructuring civic engagement in everyday life. In Proceedings of the 5th Decennial Aarhus Conference: Critical Alternatives, Aarhus, Denmark, 17 - 21 August 2015. Aarhus, Denmark: Aarhus University Press, pp. 145-156.

Latour, Bruno (1987). Science in action: How to follow scientists and engineers through society. Cambridge, MS: Harvard University Press.

Latour, Bruno (1993). We have never been modern. New York: Harvester Wheatsheaf.

Latour, Bruno (1999). Pandora's hope - essays on the reality of science studies. Cambridge, MS: Harvard University Press.

Larkin, Brian (2013). The Politics and Poetics of Infrastructure. Annual Review of Anthropology, vol. 42, pp. 327-343.

Law, John (2004). After Method: Mess in Social Science Research. New York: Routledge.

Le Dantec, Christopher A.; and Carl DiSalvo (2013) Infrastructuring and the formation of publics in participatory design. Social Studies of Science, vol. 42, no. 2, pp. 241264.

Marcus, George E. (1995). Ethnography in/of the world system: The emergence of multi-sited ethnography. Annual Review of Anthropology, vol. 24, pp. 95-117.

Marcus, George E. (1998). Ethnography through Thick and Thin. Princeton, NJ: Princeton University Press.

Marcus, George E. (2007). Collaborative Imaginaries. Taiwan Journal of Anthropology, vol. 5, no. 1, pp. 1-17.

Mayernik, Matthew S.; Jillian C. Wallis; and Christine L. Borgman (2013). Unearthing the Infrastructure: Humans and Sensors in Field-Based Scientific Research. Computer Supported Cooperative Work (CSCW), vol. 22, no. 1, pp. 65-101.

Menendez-Blanco, Maria; Antonella De Angeli; and Maurizio Teli (2017). Biography of a Design Project through the Lens of a Facebook Page. Computer Supported Cooperative Work (CSCW), vol. 26, no. 1, pp. 71-96.

Mol, Annemarie (2002). The Body Multiple: Ontology in Medical Practice. Raleigh, NC: Duke University Press.

Mol, Annemarie; and John Law (2002). Complexities: An Introduction. In John Law; and Annemarie Mol (eds.): Complexities: Social Studies of Knowledge Practices. Raleigh, NC: Duke University Press, pp. 1-22.

Mongili, Alessandro; and Giuseppina Pellegrino (eds.) (2014). Information Infrastructure(s): Boundaries, Ecologies, Multiplicity. Newcastle: Cambridge Scholars Publishing. 
Monteiro, Eric; Neil Pollock; Olle Hanseth; and Robin Williams (2013). From Artefacts to Infrastructures. Computer Supported Cooperative Work (CSCW), vol. 2, no. 4-6), pp. 575-607.

Monteiro, Eric; Neil Pollock; and Robin Williams (eds.) (2014). Innovation in Information Infrastructures: Introduction to the Special Issue. Journal of the Association for Information Systems, vol. 15, no. 4-5, pp. i-x.

Nardi, Bonnie A.; and Yrjö Engeström Y (1999). A web on the wind: The structure of invisible work. Computer Supported Cooperative Work (CSCW), vol. 8, no. 1-2, pp. 18.

Parmiggiani, Elena (2015). Integration by Infrastructuring: The Case of Subsea Environmental Monitoring in Oil and Gas Offshore Operations. Doctoral dissertation. Norwegian University of Science and Technology, Department of Computer and Information Science. Trondheim, Norway: NTNU-trykk.

Parmiggiani, Elena (2017). This Is Not a Fish: On the Scale and Politics of Infrastructure Design Studies. Computer Supported Cooperative Work (CSCW), vol. 26, no. 1, pp. 205-243.

Parmiggiani, Elena; Eric Monteiro; and Vidar Hepsø (2015). The digital coral: Infrastructuring environmental monitoring. Computer Supported Cooperative Work (CSCW), vol. 24, no. 5, pp. 423-460.

Parmiggiani, Elena; and Eric Monteiro (2016). A Measure of 'Environmental Happiness': Infrastructuring Environmental Risk in Oil and Gas Off shore Operations. Science \& Technology Studies, vol. 29, no. 1, pp. 30-51.

Pipek, Volkmar; and Volker Wulf (2009). Infrastructuring: Toward an integrated perspective on the design and use of information technology. Journal of the Association for Information Systems, vol. 10, no. 5, pp. 447-473.

Pollock, Neil; and Robin Williams (2010). e-Infrastructures: How Do We Know and Understand Them? Strategic Ethnography and the Biography of Artefacts. Computer Supported Cooperative Work (CSCW), 19(6), 521-556.

Pors, Jens K.; Dixi Louise Henriksen; Britt Ross Winthereik; and Marc Berg (2002). Challenging divisions: Exploring the intersections of ethnography and intervention in IS research. Scandinavian Journal of Information Systems, vol. 14, no. 2, pp. 3-7.

Ribes, David (2014). Ethnography of Scaling Or, How to fit a national research infrastructure in the room. In Proceedings of the CSCW2014 Conference on Computer Supported Cooperative Work, Baltimore, MD, USA, 15 - 19 February 2014. New York: ACM Press, pp. 377-391.

Ribes, David; and Thomas A. Finholt (2009). The long now of technology infrastructure: articulating tensions in development. Journal of the Association for Information Systems, vol. 10, no. 5, pp. 375-398.

Ribes, David; and Charlotte P. Lee (2010). Sociotechnical studies of cyberinfrastructure and e-research: Current themes and future trajectories. Computer Supported Cooperative Work (CSCW), vol. 19, no. 3-4, pp. 231-244.

Star, Susan Leigh (1999). The Ethnography of Infrastructure. American Behavioral Scientist, vol. 43, no. 3, pp. 377-391.

Star, Susan Leigh (2002). Infrastructure and ethnographic practice: Working on the fringes. Scandinavian Journal of Information Systems, vol. 14, no. 2, pp. 107-122.

Star, Susan Leigh; and Geoffrey C. Bowker (2002). How to infrastructure? In L.A. Lievrouw and S.L. Livingstone (eds.) The Handbook of New Media. Social Shaping and Consequences of ICTs. London: Sage, pp. 151-162. 
Star, Susan Leigh; and Karen Ruhleder (1994). Steps towards an ecology of infrastructure: Complex problems in design and access for large-scale collaborative systems. In Proceedings of the CSCW1994 Conference on Computer Supported Cooperative Work, Chapel Hill, North Carolina, USA, 22 - 26 October 1994. New York: ACM Press, pp. 253-264.

Star, Susan Leigh; and K. Ruhleder (1996). Steps toward an Ecology of Infrastructure: Borderlands of Design and Access for Large Information Spaces. Information Systems Research, vol. 7, no. 1, pp. 111-134.

Star, Susan Leigh; and Anselm Strauss (1999). Layers of Silence, Arenas of Voice: The Ecology of Visible and Invisible Work. Computer Supported Cooperative Work (CSCW), vol. 8, no. 1-2, pp. 9-30.

Strathern, Marilyn (1989). Between a Melanesianist and a deconstructive feminist. Australian Feminist Studies, vol. 10, pp. 49-69.

Strathern, Marilyn (1992). Parts and wholes: Refiguring relationships in a post-plural world. In Adam Kuper (ed.): Conceptualizing Society. London: Routledge, pp. 75104.

Strathern, Marilyn (1995). The Relation: Issues in Complexity and Scale. Cambridge: Prickly Pear Press.

Suchman, Lucy (1995). Making Work Visible. Communications of the ACM, vol. 38, no. 9, pp. 56-64.

Tilson, David; Kalle Lyytinen; and Carsten Sørensen (2010). Digital Infrastructures: The Missing IS Research Agenda. Information Systems Research, 21(4): 748-759.

Vertesi, Janet (2014). Seamful Spaces: Heterogeneous Infrastructures in Interaction. Science, Technology, \& Human Values, vol. 39, no. 2, pp. 264-284.

Wagenknecht, Susann; and Matthias Korn (2016). Hacking as Transgressive Infrastructuring: Mobile Phone Networks and the German Chaos Computer Club. In Proceedings of the CSCW2016 Conference on Computer Supported Cooperative Work, San Francisco, CA, USA, 27 February - 02 March 2016. New York: ACM Press, pp. 1104-1117.

Williams, Robin; and Neil Pollock (2012). Research Commentary —Moving Beyond the Single Site Implementation Study: How (and Why) We Should Study the Biography of Packaged Enterprise Solutions. Information Systems Research, vol. 23, no. 1, pp. 1-22.

Winthereik, Britt Ross; Antoinette de Bont; and Marc Berg (2002). Accessing the world of doctors and their computers: 'Making available' objects of study and the research site through ethnographic engagement, Scandinavian Journal of Information Systems, vol. 14, no. 2, pp. 47-58.

Winthereik, Britt Ross; and Helen Verran (2012). Ethnographic stories as generalizations that intervene. Science Studies, vol. 25, no. 1, pp. 37-51.

Wong, Richmond Y.; and Steven J. Jackson (2015). Wireless Visions: Infrastructure, Imagination, and US Spectrum Policy. In Proceedings of the CSCW2015 Conference on Computer Supported Cooperative Work, Vancouver, BC, Canada, 14 - 18 March 2015. New York: ACM Press, pp. 105-115.

Zimmerman, Ann; and Thomas A. Finholt (2007). Growing an infrastructure: The role of gateway organizations in cultivating new communities of users. In GROUP2007: Proceedings of the 2007 international ACM conference on Supporting group work, Sanibel Island, FL, USA, 04 - 07 November 2007. New York: ACM Press, pp. 239-248.

Zittrain, Jonathan L. (2006). The Generative Internet. Harvard Law Review, vol. 119, pp. 1974-2040. 